\title{
INSTITUTIONAL ABUSE - CHARACTERISTICS OF VICTIMS, PERPETRATORS AND ORGANSATIONS: A SYSTEMATIC REVIEW
}

\section{Abstract}

\section{Background}

Abuse of vulnerable adults in institutional settings has been reported from various countries; however, there has been no systematic review of the characteristics of the victims and their abusers. Our aim was to identify and synthesize the literature on victims and perpetrators of abuse in institutions and the characteristics of the institutions where abuse occurs in order to inform interventions to prevent such abuse.

\section{Methods}

Searches of MEDLINE (OVID), CINHAL (EBSCO), EMBASE (OVID) and PsychINFO (OVID) databases identified 4279 references. After screening of titles and abstracts, 123 citations merited closer inspection. After applying inclusion and exclusion criteria, 22 articles were included in the review.

\section{Results}

Our review suggested that the evidence available on risk factors is not extensive but some conclusions can be drawn. Client, staff, institutional and environmental factors appear to play a role in increasing the risk of abuse. Cases of abuse may be underreported.

\section{Conclusions}

Vulnerable clients need closer monitoring. Clients and staff may lack the awareness and knowledge to identify and report abuse. Institutions should take proactive steps to monitor clients, train staff and devise systems that allow for the identification and reporting of incidents of abuse and take steps to prevent such incidents. Staff need education and awareness of institutional policies to identify and report abuse. There is a need for further research into the association between the individual client, staff and institutional characteristics and abuse. Such information may be useful in quantifying risk to individual clients and planning their care.

\section{Keywords}

Characteristics, staff, adults, ulnerable, caregiver, institution, abuse 


\section{Introduction}

The prevalence of abuse of vilnerable adults is high and the number of incidents of abuse in institutions remains almost as high as that in the community. In a UK study of 6148 adult protection referrals, $46 \%$ related to people in residential or supported living services (1). Progress has been made to identify, monitor and prevent such abuse in institutions and communities throughout the world.

The Universal Declaration of Human Rights (1948) (2) was the most significant first step taken towards promoting awareness of and safeguarding from abuse. Further significant international agreements included the United Nations Declaration on the Rights of Mentally Retarded Persons (1971) (3), the Convention on the Elimination of all Forms of Discrimination against Women (1979) (4), the Convention against Torture and other Cruel, Inhuman or Degrading Treatment or Punishment (1984) (5) and the Convention on the Rights of Persons with Disabilities (2006) (6).

In Europe, the European Convention on Human Rights (7) has been the most significant treaty to protect human rights and fundamental freedoms. It came into force in 1953 and 47 Council of Europe member states are now signatories to the convention. In the UK, legislation such as the Mental Health Act (1983) (8), the Human Rights Act (1998) (9), the Mental Capacity Act (2005) (10) and the Safeguarding Vulnerable Groups Act (2006) (11) were enacted to protect and safeguard vulnerable people.

In spite of such national and international agreements and legislation, incidents of institutional abuse continue to be reported from all over the world. Examples from the UK include cases of abuse at the high-secure hospitals, Rampton (12) and Ashworth (13), abuse of intellectually-disabled clients at the care home Winterbourne View (14) and, more recently, the investigation into the sexual assaults against large numbers of individuals over many decades in several NHS hospitals by the TV presenter Jimmy Saville (15). 
This systematic review aimed to collate information on the characteristics of adults (over the age of eighteen years old) who are victims of abuse in institutional settings, the characteristics of professionals who abuse in institutions as well as the environmental factors within institutions, such as cultural factors and management deficiencies, that may allow or fail to prevent abuse in institutions. We followed the PRISMA guidance (16) as far as applicable in reporting methods and results of this systematic review.

\section{Definition of 'abuse'}

Various international organisations have defined specific forms of abuse but we could not identify an agreed definition for 'abuse in institutional settings'. The Oxford dictionary defines 'abuse' as 'Use (something) to bad effect or for a bad purpose'. The World Health Organisation defines 'Elder abuse' as "a single, or repeated act, or lack of appropriate action, occurring within any relationship where there is an expectation of trust which causes harm or distress to an older person" (17). Elder abuse can take various forms such as physical, psychological or emotional, sexual and financial abuse. It can also be the result of intentional or unintentional neglect. Even though the above description was given not in the context of adult clients in institutions, the authors feel that this definition is relevant in the context of abuse of adults in institutional settings and we have therefore adopted this definition for the purpose of our review.

\section{Methods}

\section{Searches}

Database searches were undertaken on $13^{\text {th }}$ March 2013 . The following databases were searched: MEDLINE (OVID) from the year 1950 onwards, CINHAL (EBSCO) from 1982 onwards, EMBASE (OVID) from 1980 onwards and PsychINFO (OVID) from 1806 onwards. Search terms used covered the population of interest, types of abuse and settings and included: elder abuse, violence, abuse, abused, maltreat ${ }^{*}$, neglect, violence, exploit, sexual, physical, mental, emotional, elder, financial, intellectual disability, developmental disabilities, disabled Persons, disab*, impair*, physical, mental, intellectual, learning, cognitive, 
wulnerable, frail, decline, dementia, Alzheimer, adult, man, woman, women, elderly, older person, older people. The full details of the search strategy can be obtained from the authors upon request. Identified citations were subjected to a selection process applying exclusion and inclusion criteria as described below by two of the authors (YK, MF). Reviews were not included but their citations were examined for references to primary studies that may meet the inclusion criteria. The search identified two non-English language articles; one was German and was analysed by one of the authors who is a German speaker (BV), the other article was Spanish and was excluded.

\section{Inclusion criteria}

Studies, including case studies and series, published in peer reviewed journals, dissertations, inquiries into specific instances of abuse, or other publications which describe characteristics of either the victims or the perpetrators of abuse or the environmental or organisational factors contributing to abuse in institutions were included. Only studies on abuse of adults (over the age of eighteen years) in institutions were considered.

\section{Exclusion criteria}

Studies of abuse of children or of adult victims in non-institutional settings were excluded as were studies where the perpetrator was not in the role of professional caregiver to the victim or where the characteristics of either the victims or the perpetrators or environmental factors of abuse were not described. Studies which included both individuals over and under eighteen years of age were excluded if data about the adult population could not be separated. Similarly, studies that had components addressing abuse in both institutional and domestic settings were included but only if information on institutional abuse could be separately identified.

\section{Selection of studies}

Using titles, keywords and abstracts, two of the authors (YK, MF) screened all references obtained in the searches for possible inclusion. If a publication appeared relevant from initial 
screening, full text papers were obtained and examined in accordance with our inclusion and exclusion criteria. The selection process is summarised in Figure 1 as a flow chart.

\section{$\underline{\text { Results }}$}

The searches resulted in 4279 citations which were subjected to the selection process as represented in Figure 1 resulting in the identification of 22 relevant articles included in this review. The information from the selected articles was analysed in terms of the population groups affected and type of abuse; study characteristics are represented in Table 1. Risk factors that were identified in multiple studies are described below organised by: characteristics of the victims, characteristics of perpetrator and organisational factors. These risk factors are summarised in Table 2.

\section{Characteristics of victims}

\section{Gender}

Many but not all studies have identified female gender of the client as a risk factor using different methods, including case file reviews and interviews of staff as well as clients. Female individuals with intellectual disability seem to be at particular risk of sexual abuse with up to $3 / 4$ of victims being female as identified in (18) and (19). A higher risk of other types of abuse, including physical and psychological, neglect, maltreatment and deprivation of rights, has also been reported for elderly individuals, albeit with smaller female - male ratios (20). Zemp (21) reported from a study on individuals with physical, mental and/or psychological disability that a higher proportion of female participants $(64 \%)$ compared to males $(50 \%)$ indicated that they had been sexually exploited. Of note is one study (22) which indicated higher rates of abused females according to staff but not client statements, indicating possibly that abuse towards males is under detected. Marchetti et al.'s (23) study of intellectually-disabled victims of sexual abuse and Rusch et al.'s (24) study of intellectually-disabled victims of physical abuse failed to find significant gender differences. Taken together with the overrepresentation of 
females in staff reports, this might suggest that once detected male cases are more rigorously prosecuted.

\section{Age}

Findings for age were not consistent though particular age groups were identified to be at higher risk of abuse in some studies. Turk et al. (18) reported that, in an intellectually-disabled population, the largest percentage of reported cases of abuse was in the age range of 21-30 years while Roberto et al. (25) found that middle aged and older clients were significantly more likely to be exposed to unwelcome conversation on sexual activity from perpetrators. Studies on cognitive impairment as outlined below (17) (25) suggest that age is a risk factor only through its association with cognitive decline but not independently.

\section{Dementia}

Dementia and decreased cognitive function was identified as a risk factor for abuse in some studies. Natan et al. (20) reported that elderly women with dementia had the highest risk of experiencing mental neglect. Conner et al. (26) indicated that, according to the perceptions of relatives of those in care, cognitive impairment was a risk factor only if it resulted in verbal or physical aggression or resistance to care. They also concluded that age in conjunction with cognitive impairment was a risk factor but not cognitive impairment on its own.

\section{Intellectual disability}

Intellectual disability seems to be a significant risk factor for abuse as identified in most studies reporting on this factor, particularly when severe. A number of studies focusing specifically on samples of intellectually disabled clients who have been victims of different types of abuse have found that the majority of those disabled had a severe or profound intellectual disability (24) (27) (28) (29). There were some discrepant findings though that suggest a more complex relationship between degree of disability and likelihood of abuse might apply, at least for some groups. Furey (19) reported that for male intellectually disabled clients there were more victims of abuse in the severe intellectual disability group while for females there were more victims in the mild intellectual disability group. Marchetti et al. (23) 
reported that abused clients tended to be higher functioning than non-abused clients on both $\mathrm{IQ}$ and adaptive behaviour levels.

\section{Physical disability}

Physical disability was identified as a risk factor in a number of studies as reported by relatives (26), clients (29) and through case file reviews $(23,26,27)$. High rates of physical disabilities have been reported in those abused. E.g., Turk et al. (18), in a review of sexual abuse in an intellectual disability population, found that $70 \%$ of victims had other handicaps and $25 \%$ had more than one handicap. Teaster et al. (30) reported that $50 \%$ of victims of alleged abuse could not ambulate without some assistance. Rusch et al. (24) found that 39 out of 80 clients with intellectual disability who were victims of physical abuse also had a physical disability. Specific impairments, independent of type of abuse, identified in the literature included impaired ambulation, hearing and vision as well as the need for physical, mechanical or personal assistance and incontinence.

\section{Challenging Behaviours}

Studies reported an association between client aggression and being the victim of abuse and the incident rates of challenging behaviours in samples of abused individuals were high. Goergen et al (31) found that some carers attributed the cause of abuse to the behaviour of clients who were mentally disturbed, provoked nurses and acted aggressively towards them. Turk et al. (18) found that, in their intellectually disabled population, $41 \%$ of victims had psychiatric or behavioural problems. Rusch et al. (24) found that just over half of the abused clients in their study were aggressive themselves. According to Furey (19), among mentally retarded adult men who were victims of sexual abuse, the victims had high rates of being subjected to physical or mechanical restraint and a higher rate of use of behaviour modifying drugs.

Comparing abused with non-abused clients, Zirpoli et al. (28) noted that the abused group showed significantly more violent $(p<0.04)$, disruptive $(p<0.05)$, rebellious $(p<0.02)$ and hyperactive behaviour $(p<0.04)$ compared to the non-abused group. Bužgová et al. (22) 
identified that elderly clients who were confrontational $(p<0.001)$ and aggressive $(p<0.05)$ were more often abused. McCartney et al. (27) noted that maladaptive behaviours such as physical violence, self-harm, disruptive behaviour, rebellious behaviour, hyperactivity, property destruction and socially offensive behaviour increased the probability of being abused among persons with intellectual disability. In the abused client sample, $66 \%$ were involved in an individual behavioural management program and $40 \%$ received a drug to control their behaviour compared to the comparison client sample where these figures were $48 \%$ and $26 \%$ respectively.

\section{Other client related factors}

Individuals with no outside contact and those having been abused in the past were more likely to be victims of abuse. Bužgová et al. (22) found that clients who were visited rarely were more likely to be physically abused compared to those with regular visits $(P<0.05)$. Similarly, Shaw (32) reported that some investigators of abuse in an elderly people's home concluded that clients who had no family or other regular visitors seemed more prone to being neglected. McCartney et al. (27) noted in their study on an intellectual disability population that $28 \%$ of the confirmed-abused group had a history of abuse within the previous 12 months compared to only $10 \%$ of the randomly selected comparison group.

\section{Characteristics of professionals who abuse in institutions}

\section{Gender}

Multiple studies have identified gender of staff as to be a risk factor for being an abuser. Studies have described an overrepresentation of males in samples of abusers compared to the general - usually predominantly female - workorce. Based on analyses of reports of confirmed abuse, McCartney et al. (27) noted that $41 \%$ in the abuser group were male compared to $37.5 \%$ in the randomly selected carer group. Hussein et al. (33) reported an over-representation of men, with $31 \%$ compared to an average of $15 \%$ in the workforce. Three studies in intellectually-disabled populations (18) (23) (27) reported that male staff committed proportionately more abuse than females. However, a study based on an 
anonymous staff survey of those working with adults with intellectual disabilities found equal numbers of males and females reported as having abused suggesting, maybe, a bias in the way abuse cases are handled and legal sanctions applied in the two genders.

\section{Age}

As for age of victim, findings regarding the age of perpetrator were somewhat mixed though more studies seem to suggest that younger staff are at a higher risk of becoming abusers than older staff. McCartney et al. (27) reported a significant age difference between abusers (mean age 35.13) and a randomly selected group of carers (38.21). Hussein et al. (33) found that older staff (aged 50 and over) were more likely to be accused of committing physical and sexual abuse compared with staff younger than 25 years of age. Staff aged 35-49 years (OR $=4.05 ; P=<0.001)$ were more likely to be accused of sexual abuse compared to the other age groups while younger staff were more likely to be referred for financial abuse. Strand et al.'s (34) study on abuse of adults with intellectual difficulties found that most perpetrators were either under thirty (41\%) or over forty (38\%) years of age. Pillemer et al. (35) reported that younger staff more frequently resorted to psychological abuse. Only Bužgová et al. (22) reported no significant relationship between elder abuse and an employee's age.

\section{Role of the carer and the level of training}

Studies reported that most of the abusers identified are non-trained, direct care staff; however, this staff group also represents the largest group of staff in institutions and, thus, without comparisons with staffing levels generally, conclusions are somewhat difficult to draw. Hussein et al.'s (33) analysis of characteristics of abusing staff reported that $67 \%$ were frontline care staff, $11 \%$ were team leaders/supervisors, $9 \%$ were nurses working in social care, $8 \%$ were managers or deputies without direct care responsibility and $4 \%$ were nonclinical staff with no direct care responsibility. Marchetti et al. (23) reported that unqualified direct care staff were in the majority of the staff committing abuse. Natan et al. (20) reported that trained grades of staff were less likely to hold negative attitudes towards elders compared to non-trained staff. 


\section{Qualification}

Consistent with the findings on the role and level of training, studies have also found that less qualified staff were more likely to abuse. Cambridge (36) reported that lack of qualification, professional skills to recognise and report abuse and low competence and experience to perform essential care tasks were identified in abusing staff. McCartney et al. (27) reported that direct care staff members with no college degrees who provided client service for at least one third of their work shift committed $87 \%$ of the abuse incidents and reported $46 \%$ of the cases. The perpetrators were mostly second shift workers $(11.00 \mathrm{am}-3.00 \mathrm{pm})$ and were in the newer staff category.

\section{Personality}

A number of studies have considered personality traits in relation to becoming an abuser. Bužgová et al. (22) reported that carers who abused clients considered themselves more dominant or authoritative than non-abusers $(P<0.05)$; psychological abusers were significantly more likely to describe themselves as exhausted or dominant $(P<0.05)$. Natan et al. (20) reported that the less individuals felt personally ambitious, the greater the risk of perpetrating various forms of maltreatment. Other factors described included not being suitable for the job, lack of empathy and lack of competence to handle conflict situations and wanting to vent their rage on someone (31).

Furthermore, $62.5 \%$ and $57 \%$ of staff who believed that clients were like children reported that they committed acts of physical and psychological abuse respectively; $42 \%$ and $35 \%$ of staff who had conflicts with patients reported that they had committed acts of physical and psychological abuse respectively (37).

Not surprisingly, having history of previously abusing clients was associated with later abuse, with McCartney et al. (27) reporting that in staff who abused clients currently, $21.5 \%$ had done so too in the previous year, while this was only the case in $6 \%$ of the randomly selected carer group. Cambridge (36), in an inquiry into abuse of two clients with severe intellectual disability and challenging behaviours, found that staff who abused clients also intimidated other staff 
and service managers. Shaw (32) reported that substance abuse, dysfunctional family situations and a history of involvement in domestic abuse were all associated with abuse.

\section{Working conditions}

A number of studies have identified stressful working conditions and burnout to be related to becoming an abuser (22) (37). High burnout symptoms and high conflict levels also seemed to directly affect the quality of staff-client interactions and appeared to be stronger predictors of abuse than demographic variables such as age, education, role and years of experience. The level of burnout was found to be an especially strong predictor of psychological abuse (37). Working when unwell and the absence of sick leave were also found (32).

Bužgová et al. (22) reported that employees perpetrating psychological and physical abuse were more often dissatisfied with their working conditions. Abusers did not feel sufficiently motivated by their managers, considered their job stressful (22) and felt they had to get their work done quicky (31). Pillemer et al.'s (37) survey reported that, of staff who were frequently thinking of quitting, 58.9\% and 51.5\% confessed to committing acts of physical and psychological abuse respectively.

\section{Stressors}

As well as stress at work, personally stressful situations were associated with a higher risk of abusing residents. In one study of nursing home staff (37), 49.2\% of staff who reported going through stressful personal life situations confessed to committing acts of psychological abuse. Goergen et al. (31) reported that having psychological stress (Pearson correlation coefficient, $r=0.33, p=<0.01$ ) and being emotionally exhausted (Pearson correlation coefficient, $r=$ 0.23, $p<0.05$ ) could contribute to abuse. Shaw (32) reported that physical exhaustion, emotional depletion due to multiple problems at home and work and economic inequality were factors that increased the risk of abuse.

\section{Characteristics of institutions where abuse occurs}




\section{Organisation and Management}

As well as factors in victims and staff, certain features in the organisations themselves facilitate the commission of abuse. Pillemer et al. (37), Teaster et al. (30) and Roberto et al. (25) stipulated that all types of elder abuse were underreported. Abuse might have occurred several times before a member of staff was charged (33). This could be due to a lack of evidence but also due to a lack of interest in pursuing these cases.

Cambridge (36) described from his investigation of cases of abuse in a residential service that management had an inward looking culture and a punishing regime and distanced themselves from direct care staff. The service resisted input and involvement of outside professionals. Places where abuse occurred were isolated within the organisation and the staff group isolated from peer scrutiny. This finding is also related to a point Mansell et al. (1) made, following an analysis of over 6000 adult protection referrals, namely that abuse in care homes was often likely to be perpetrated by multiple abusers.

The findings reported above regarding work load and burnout are also of relevance here and carers often rated staff shortage and work overload as reasons for abuse and neglect (29). Cambridge (36) reported low pay, low social status and poor working conditions as important factors contributing to abuse. Goergen et al (31) reported that elderly care staff felt that reduced financial resources were a factor contributing to abuse.

There is little evidence on the effect of particular policies on the likelihood of abuse occurring though participants in one study felt that a stricter policy by the nursing director to deal with any form of abuse had had a positive effect (23).

\section{Environment and shift pattern}

Isolation is an important facilitator for abuse. Turk et al. (18) reported that the highest rates of abuse were likely to occur when the victim was the only person in a position to report the abuse. Furey (19) reported that opportunity was an important factor in sexual abuse. In residences, victims may be readily available and unable to escape from the perpetrator. 
Nevertheless abuse can occur in all physical spaces and at all times: McCartney et al. (27) reported that abuse occurred in residential areas in $60 \%$, during leisure activities in $29 \%$ and during personal hygiene care in $16 \%$ of cases. Mercer et al. (38) further highlighted the latter situation in describing that rough handling frequently occurred during bathing and dressing. Furthermore, physical abuse most frequently occurred in the $3.00 \mathrm{pm}-6.00 \mathrm{pm}$ period and was most commonly (30\%) perpetrated in the living area. Marchetti et al. (23) reported that $40 \%$ of abuse cases were committed during the first shift (6.00 am $-9.00 \mathrm{am})$ and $46 \%$ during the second shift (11.00 am - $3.00 \mathrm{pm})$.

\section{Staff management}

Cambridge (36) described that, where the principal alleged abuser was able to gain control over and bully staff and service managers by a combination of collusion and intimidation, abuse may not be dealt with rigorously. Staff supervision was ineffective and the prevention of abuse received a low priority due to other pressures. Management and peer scrutiny was particularly lacking during nights and in monitoring the provision of personal and intimate care. There was poor development, implementation and monitoring of interventions designed to reduce the frequency, severity or duration of challenging behaviour. Lack of guidance resulted in the development of inappropriate and abusive staff responses. This organisational environment created barriers and disincentives to disclosure. New staff were encouraged to assault clients when they presented with aggressive behaviour by both example and deception.

\section{Discussion}

The aim of this systematic review was to identify and synthesize the literature on abuse in institutions. Despite measures by governments, abuse seems to be a daily matter and many of the studies suggest the actual number of cases of abuse are underestimated (1) (30) (27) (37) given that not all cases of abuse are detected. Challenges such as absence of reliable evidence coupled with a tendency to view abuse as not a very serious issue, lead to very few prosecutions and convictions of offenders. This is more so in the context of sexual abuse. It 
is, however, encouraging to find that progress has been made in reducing abuse due to research and evaluation regarding this topic. One of the studies (22) has resulted in a national policy to increase social supervision of care homes for the elderly. In addition, especially with regards to sexual abuse, increased awareness and heightened media interest has led to multiple cases of sexual abuse being highlighted (18).

A number of relevant factors in terms of victim and perpetrator characteristics as well as those related to institutions in which abuse takes place are identified in our review; the identification of these factors may aid in developing strategies to reduce institutional abuse of vulnerable adults.

\section{Victims}

The most important victim factors are relatively consistently reported and include being female, having decreased cognitive function, being aggressive and violent and having no regular visitors. The knowledge of the risk factors identified may allow better identification of vulnerable clients, quantification of the risk, monitoring, and safeguarding of those at risk Factors identified have face validity and are related to an increase in the vulnerability of the client although one possible reason for the female gender to be over represented could be that women live longer than men and hence their time at risk of abuse is greater. It is also possible that men may report less abuse due to social stigma associated with being identified as a victim of abuse. However, this conclusion is not supported by the observation that studies based on self-report by clients indicate less profound gender differences (22). Another reason for the gender difference might therefore be that cases are dealt with differently once identified with more cases of female victims being further investigated and prosecuted(39).

Age of the client seems to be a risk factor only when it was associated with cognitive impairment. Intellectual disability of victims made it difficult for them to understand the criminal nature of their experiences and to make relevant disclosures. Studies reported an association between client aggression and being the victim of abuse. However, without longitudinal studies it is difficult to conclude that there is a causal relationship between the two observations and, if so, in which direction. Encouraging and supporting clients in social relationships outside the institution might offer a degree of protection; as such befriending 
schemes that should be expanded. Clients who need personal care, such as those suffering from incontinence, should have appropriate care plans in place and should receive adequate support in a safe environment by well trained staff.

\section{Staff}

Being male, non-trained, frontline care staff increases the risk of perpetrating abuse. Male gender was identified in many studies as a risk factor but one study (34), based on anonymous reporting by staff members, suggests equal numbers of male and female perpetrators. This may, again, suggest a different perception of risk and subsequent steps of the investigation in the two genders as found elsewhere in the criminal justice system (39) (40). The risk factors identified for carers call for more training, in particular around the identification of abuse, but also generally to increase knowledge and skills in order for staff to feel confident and valued in their roles. Individuals who may require closer supervision need to be identified. Pre-service screening for staff working with people considered to be at risk of abusive treatment (28) and background checks (19) may help in selecting staff that will pose a lower risk at becoming abusers.

\section{Institutions}

Factors such as environments where the victim is the only person in a position to report the abuse, situations that generate opportunities to abuse, inward looking culture, ineffective staff supervision, lack of policies to deal with abuse, reduced financial resources, etc. seem to increase the risk of abuse. Knowledge of these factors may help in the development of policies around the monitoring of vulnerable clients, staff training, hospital environment, and support to clients and staff when abuse incidents are identified. New staff should be provided with training to help them identify abuse and institutions provided with resources to identify abuse at the earliest opportunity and to prevent serious incidents. Such training should be updated at regular intervals. There should be well-advertised points of contact for staff to approach when they suspect or identify abuse. Institutions should encourage an environment of openness where all events can be openly discussed. 
Findings around burnout and stress call for staff support to effectively deal with stressors at and outside work They should be well motivated to work with difficult individuals and receive training to manage aggressive behaviours in a safe and professional way using conflictresolution measures, de-escalation techniques and approved restraint and rapid tranquilisation procedures. Restraint techniques used by staff should be periodically reviewed and updated to promote the least restrictive and harmful alternative for an agitated client. Institutions should also be equipped with facilities such as quiet rooms and structured day activities including physical exercise for clients to reduce the risk of aggression (41). Areas in the institution and periods (weekend, night shifts) recognised to provide greater potential for abuse should be closely monitored. Strict policies to deal with staff who abuse should be implemented. Regular community meetings involving staff and clients to discuss policies and grievances may also contribute to better understanding and reduction in aggressive episodes. Institutions should promote safe environments for staff, including steps to prevent intimidation of vulnerable staff by implementing strict anti-bullying policies. Institutions should be open to scrutiny from both within and outside the organisation. Management should respond quicky and effectively to deal with any concerns raised by members of staff or clients.

\section{References}

1 Mansell J, Beadle-Brown J, Cambridge P, Milne A, Whelton B. Adult protection: incidence of referrals, nature and risk factors in two English local authorities. Journal of Social Work 2009; 9(1):23-38.

2 Universal Declaration of Human Rights (1948)

http://daccess- dds-ny.un. org/doc/R ESOLUTION/GEN/NR 0/043/88/IM G/NR 004388. pdf?

OpenElement

3 United Nations Declaration on the Rights of Mentally Retarded Persons (1971)

http://www. ohchr. org/Documents/Profes sional Inter est/r es 2856.pdf

4 Convention on the Elimination of all Forms of Discrimination against Women (1979)

http://www. ohchr. org/Documents/Profes sional Inter est/c edaw.pdf 
5 Convention against Torture and other Cruel, Inhuman or Degrading Treatment or Punishment (1984)

http://www.ohchr.org/D oc uments/Pr of essionallnter est/cat. pdf

6 Convention on the Rights of Persons with Disabilities (2006)

http://www.un.org/dis abiliti es/c onventi on/conventionfull.s html

7 European Convention on Human Rights (1950)

http://www.echr.coe.int/Documents/C onventi on_ENG.pdf

8 The Mental Health Act (1983)

http://www.l egislati on.gov.uk/ukpga/1983/20/c ontents

9 The Human Rights Act (1998)

http://www.l egislati on.gov.uk/ukpga/1998/42/c ontents

10 The Mental Capacity Act (2005)

http://uww.l egislation.gov.uk/ukpga/2005/9/contents

11 The Safeguarding Vulnerable Groups Act (2006)

http://uww.l egislati on.gov.uk/ukpga/2006/47/contents

12 Boynton, J. (1980) Report of the Review of Rampton Hospital. London: HMSO (Cmnd. 8073)

13 Fallon, P., Bluglass, R., Edwards, B. and Daniels, G. (1999a) Report of the

Committee of Inquiry into the Personality Disorder Unit, Ashworth Special Hospital.

14 Transforming care: a national response to Winterbourne View hospital Author -

Department of Health, UK.2012.

https://www.g ov.uk/g over nment/uploads/system/upl oads/attachment_data/fil e/213215/fi nal -

report.pdf 
15 NHS and Department of Health investigations into Jimmy Savile; Kate Lampard, 2014, https://www.g ov.uk/g over nment/coll ecti ons/nhs- and-department-of-heal th-i nvestigati ons-intojimmy-savile

16 Preferred Reporting Items for Systematic Reviews and Meta-Analyses (PRISMA) http://www. pris ma-statement.org/ $19^{\text {th }}$ June 2016

17 Elder abuse - World Health Organization http://www.who.int/ageing/projects/elder_abus e/en/

18 Turk V, Brown $\mathrm{H}$. The sexual abuse of adults with learning disabilities: Results of a two year incidence survey. Mental Handicap Research. 1993;6(3):193-216 ST.

19 Furey E. Sexual abuse of adults with mental retardation: Who and Where. Mental retardation. 1994; 32(3),173-180.

20 Natan M, Lowenstein A, Eisikovits Z. Psycho-social factors affecting elders' maltreatment in long-term care facilities. International Nursing Review. 2010;57(1):113-20.

21 Zemp A. Sexual violence against people with handicaps in institutions. [German] Sexualisierte Gewalt gegen Menschen mit Behinderung in Institutionen." Praxis der Kinderpsychologie und Kinderpsychiatrie. 2002;51(8):610-625 ST.

22 Bužgová R, Ivanová K. Violation of ethical principles in institutional care for older people. Nursing Ethics. 2011;18(1):64-78.

23 Marchetti A, McCartney J. Abuse of Persons with Mental Retardation: Characteristics of the Abused, the Abusers, and the Informers. Mental Retardation. 1990;28 (6):361-71.

24 Rusch R, Hall J, Griffin H. Abuse-provoking characteristics of institutionalized mentally retarded individuals. American Journal of Mental Deficiency. 1986;90(6): 618-624.

25 Roberto K, Teaster P. Sexual abuse of vulnerable young and old men. Journal of Interpersonal Violence. 2005;11(4):473-504 
26 Conner T, Prokhorov A, Page C, Fang Y, Xiao Y, Post L. Impairment and Abuse of Elderly by Staff in Long Term Care in Michigan: Evidence from Structural Equation Modelling. Journal of Interpersonal Violence. 2011;26(1)21-33.

27 McCartney J, Campbell V. Confirmed abuse cases in public residential facilities for persons with mental retardation: a multi-state study. Mental Retardation. 1998;36(6):465-73 ST.

28 Zirpoli T, Snell M, Loyd B. Characteristics of persons with mental retardation who have been abused by caregivers. The Journal of Special Education. 1987;21(2):31-41.

29 Nosek M, Foley C, Hughes R, Howland C. Vulnerabilities for abuse among women with disabilities. Sexuality \& Disability. 2001;19(3): 177-189.

30 Teaster P, Roberto K. Sexual abuse of older adults: APS cases and outcomes. The Gerentologist. 2004; 44(6): 788-796.

31 Goergen T. Stress, conflict, elder abuse and neglect in German nursing homes: A pilot study among professional caregivers. Journal of Elder Abuse \& Neglect. 2001;13(1):1-26.

32 Shaw M. Nursing home resident abuse by staff: Exploring the dynamics. Journal of Elder Abuse \& Neglect. 1998; 9(4):1-21.

33 Hussein S, Stevens M, Manthorpe J, Rapaport J, Martineau S, Harris J. Banned from working in social care: a secondary analysis of staff characteristics and reasons for their referrals to the POVA list in England and Wales. Health and Social Care in the Community. 2009;17 (5): 423-433.

34 Strand M, Benzein E, Saveman B. Violence in the care of adult persons with intellectual disabilities. Journal of Clinical Nursing. 2004;13:506-514.

35 Pillemer K, Moore D. Highlights from a study of abuse of patients in nursing homes. Journal of Elder Abuse \& Neglect. 1990;2(1/2):5-29. 
36 Cambridge P. The first hit: A case study of the physical abuse of people with learning disabilities and challenging behaviours in a residential service. Disability \& Society. 1999:14(3): $285-308$.

37 Pillemer K, Moore D. Abuse of patients in nursing homes: Findings from A survey of staff. The Gerontologist 1989; 29:314-20.

38 Mercer S, Heacock P, Beck C. Nurses' aides in nursing homes: perceptions of training, workoads, racism, and abuse issues. Journal of Gerontological Social Work 1993;21(1/2):95-112

39 Gender in the Criminal Justice System. United Nations Office on Drugs and Crime.

October 2010

https://www.unodc. org/doc uments/justice-and-prison-refor m/cri mepreventi on/E-book. pdf. $19^{\text {th }}$ June 2016

40 Statistics on Women and the Criminal Justice System

https://uww.g ov.uk/g over nment/uploads/system/upl oads/attachment data/fil e/217824/s tatis tic s-women-cjs-2010.pdf 19th June 2016

41 Violence and aggression: short-term management in mental health, health and community settings

https://www. nic e. org.uk/guidance/NG 10/chapter/1-Recommendations \#ter ms- us ed-i n-thisquideline $19^{\text {th }}$ June 2016 